\title{
Multinuclear $\left({ }^{1} \mathrm{H},{ }^{31} \mathrm{P}\right.$ and $\left.{ }^{195} \mathrm{Pt}\right) \mathrm{NMR}$ study and dynamical analysis of binuclear $\mu$-hydrido $\mu$-carbonyl Pt(I) cations with chelating diphosphines $\dagger$
}

\author{
Anna L. Bandini, ${ }^{* a}$ Guido Banditelli, ${ }^{a}$ Maria Grassi ${ }^{* a}$ and Alessandro Ponti ${ }^{* b}$ \\ ${ }^{a}$ Università degli Studi di Milano, Dipartimento di Chimica Inorganica, \\ Metallorganica ed Analitica, Via Venezian 21, 20133 Milano, Italy. \\ E-mail: maria.grassi@unimi.it; Fax: +3902 50314405; Tel: +3902 50314369 \\ ${ }^{b}$ Consiglio Nazionale delle Ricerche, Istituto di Scienze e Tecnologie Molecolari, Via Golgi 19, \\ 20133 Milano, Italy.E-mail: alessandro.ponti@istm.cnr.it; Fax: +3902 50314300; \\ Tel: +390250314280
}

Received 23rd December 2003, Accepted 16th April 2004

First published as an Advance Article on the web 27th April 2004

The dynamic behaviour of the binuclear $\mu$-hydrido $\mu$-carbonyl cations with chelating diphosphines, $\left[\mathrm{Pt}{ }_{2}(\mathrm{P}-\mathrm{P})_{2}-\right.$ $(\mu-\mathrm{H})(\mu-\mathrm{CO})]^{+}\left[\mathrm{P}-\mathrm{P}=\right.$ dppe, 1, dppp, 2, and dppb, 3] have been investigated by multinuclear $\left({ }^{1} \mathrm{H},{ }^{31} \mathrm{P}\right.$ and $\left.{ }^{195} \mathrm{Pt}\right)$ variable temperature NMR spectroscopy. The ${ }^{195} \mathrm{Pt}$ and ${ }^{1} \mathrm{H}$ results are consistent with intramolecular mutual exchange of the $\mathrm{P}$ atoms with respect to the bridging ligands in all of the complexes 1-3. A detailed dynamical analysis carried out on complexes $\mathbf{2}$ and $\mathbf{3}$ shows that the dynamical process exchanges the $\mathrm{P}$ atoms within a single diphosphino ligand, and excludes the simultaneous $\mathrm{P}$ atom exchange in both ligands. The bite of the diphosphino ligands affects the rate of this process in the order $3>2>1$. The process follows an activation law with $\Delta H^{*}=67$ and $60 \mathrm{~kJ} \mathrm{~mol}^{-1}$ for $\mathbf{2}$ and $\mathbf{3}$, respectively, so that $\mathrm{P}-\mathrm{Pt}$ bond breaking should not be involved. The positive activation entropy (17-19 $\mathrm{J} \mathrm{K}^{-1} \mathrm{~mol}^{-1}$ ) hints at a mechanism where the intermediate(s) have a less ordered structure than that of the stable complex. In accordance with the NMR results, two reactivity experiments provided further evidence of the intramolecular nature of the observed dynamics and exclude any equilibration path via $\mathrm{Pt}-\mathrm{P}$ and/or $\mathrm{Pt}-\mathrm{Pt}$ bond breaking. On these grounds, a mechanism involving rotation about a Pt-Pt bond could be proposed.

\section{Introduction}

Transition metal complexes comprising $\mathrm{M}-\mathrm{H}$ and $\mathrm{M}-\mathrm{CO}$ bonds play a fundamental role in many stoichiometric and catalytic reactions either in homogeneous and heterogeneous processes, such as hydrogenation, hydroformylation, hydrocarbon cracking and so on. ${ }^{1}$ They often undergo fluxional processes and then the dynamic behaviour of polynuclear complexes is crucial to understand the interaction of the ligands with multiple metal centres and better explain known reactions and foresee new ones. ${ }^{2}$

The hydrido and carbonyl clusters probably are the most investigated compounds as models of "multimetallic activation", and their fluxionality has been related, for example, to terminal/bridge exchange, $\mathrm{H}$ migration and so on. ${ }^{3}$ Binuclear species are regarded as the simplest models to understand reaction mechanisms at clusters or at metallic surfaces. ${ }^{4}$

During investigations on binuclear platinum hydrides, some of us obtained unusual platinum(I) species $\left[\mathrm{Pt}_{2}(\mathrm{P}-\mathrm{P})_{2}(\mu-\mathrm{H})-\right.$ $(\mu-\mathrm{CO})]^{+} \ddagger$ with several chelating diphosphines. ${ }^{5}$ Afterwards, two homologous $\mathrm{Pd}(\mathrm{I})$ complexes with dipp ${ }^{6}$ and $(S, S)$-bdpp ${ }^{7}$ ligands have been reported. The only known homologue with a monodentate phosphine, namely $\left[\mathrm{Pd}_{2}\left(\mathrm{PPh}_{3}\right)_{4}(\mu-\mathrm{H})(\mu-\mathrm{CO})\right]^{+}$, was proposed by Zudin et al. ${ }^{8}$ as a possible intermediate in

$\dagger$ Electronic supplementary information (ESI) available: Fig. S1: Effect of $k_{\mathrm{II}}$ and $k_{\text {III }}$ on the dynamical NMR lineshape computed for the foursite exchange model. Fig. S2: Linewidth contributions to hydride NMR spectra of complex 3 as a function of temperature. Fig. S3: Selected ${ }^{31} \mathrm{P}$ VT-NMR spectra for complex 3. Fig. S4: ${ }^{195} \mathrm{Pt}$ spectrum of 1 . See http://www.rsc.org/suppdata/dt/b3/b316868a/

\pm Throughout this paper the chelating diphosphino ligands (P-P) are indicated as follows: dppe, 1,2-bis(diphenylphosphino)ethane; dppp 1,3-bis(diphenylphosphino)propane; dppb, 1,4-bis(diphenylphosphino)butane; dippp, 1,3-bis(diisopropylphosphino)propane; dppcpFe, 1,1'-bis(diphenylphosphino)ferrocene; dcype, 1,2-bis(dicyclohexylphosphino)ethane; dfepe, 1,2-bis(diperfluoroethylphosphino)ethane; $(S, S)$-bdpp, $(2 S, 4 S)$-2,4-bis(diphenylphosphino)pentane. olefin insertion and in the water-gas shift reaction. The possible role of these species in reactions catalysed by organometallic $\mathrm{Pd}(\mathrm{II})$ complexes has been outlined and discussed. ${ }^{7,8}$ To elucidate their reactivity, different mono- or binuclear intermediates, originated from breaking of the Pd-Pd molecular core or from rotation around one of the bridging ligands, have been considered.

Both Pt and Pd complexes show fluxional behaviour on the NMR time scale, namely exchange between the phosphorus atoms that averages their magnetic interactions over a wide temperature range. In the solid state, X-ray crystal structure determinations $\left(\mathrm{M}=\mathrm{Pt}, \mathrm{P}-\mathrm{P}=\mathrm{dppe}^{5 b}{ }^{5 \mathrm{dppcpFe}},{ }^{5 c} \mathrm{M}=\mathrm{Pd}, \mathrm{P}-\mathrm{P}\right.$ $=\operatorname{dippp}^{6 a}$ ) showed that the two metal centres are in a tetrahedrally-distorted square-planar arrangement with $\mathrm{H}$ and $\mathrm{CO}$ as bridging ligands and short $\mathrm{M}-\mathrm{M}$ separations, as expected in diamagnetic $\mathrm{d}^{9}-\mathrm{d}^{9}$ complexes. Accordingly, $\mathbf{M}-\mu-\mathrm{C}-\mathrm{M}$ angles are rather narrow $\left(<88^{\circ}\right)$, in contrast to a description of these complexes as "metal-aldehydes", i.e., as M(II) species.

To provide a better knowledge of the structural and dynamical properties of this class of compounds, this paper reports on an extensive investigation of the variable temperature (VT) ${ }^{1} \mathrm{H}$, ${ }^{31} \mathrm{P}$ and ${ }^{195} \mathrm{Pt}$ NMR spectra of the complexes $\left[\mathrm{Pt}_{2}(\mathrm{P}-\mathrm{P})_{2}(\mu-\mathrm{H})-\right.$ $(\mu-\mathrm{CO})]^{+}(\mathrm{P}-\mathrm{P}=\mathrm{dppe}, \mathbf{1}$; dppp, 2; dppb, 3) including a detailed dynamical line-shape analysis.

\section{Results and discussion}

The binuclear $\mu$-hydrido $\mu$-carbonyl cations with chelating diphosphines, $\quad\left[\mathrm{M}_{2}(\mathrm{P}-\mathrm{P})_{2}(\mu-\mathrm{H})(\mu-\mathrm{CO})\right]^{+}(\mathrm{M}=\mathrm{Pd}, \mathrm{Pt}),^{5-8}$ (Scheme 1) show averaging of $J$-coupling to ${ }^{31} \mathrm{P}$ at high temperature, a clear indication of exchange dynamics. Since these cations contain several magnetic nuclei, they are excellent candidates for following this process by multinuclear VT-NMR spectroscopy, in particular when $\mathrm{M}=\mathrm{Pt}$. In principle, the advantage of $\mathrm{Pt}$ derivatives consists in the possibility to monitor all the core nuclei $\left({ }^{1} \mathrm{H},{ }^{13} \mathrm{C},{ }^{31} \mathrm{P}\right.$ and $\left.{ }^{195} \mathrm{Pt}\right)$ and to get to 


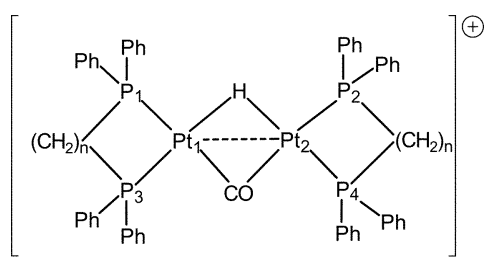

$n=2,3,4$.

Scheme 1 Schematic picture of the title compounds (1, $n=2$ : dppe; 2 , $n=3$ : dppp; $3, n=4$ : dppb) showing the numbering of the phosphorus and platinum nuclear locations.

the static situation at higher temperature, due to the known higher rigidity of $\mathrm{Pt}$ complexes. As a further benefit, the presence of the relative dilute ${ }^{195} \mathrm{Pt}$ nucleus $(I=1 / 2$; natural abundance: $33.8 \%$ ) allows one to exploit the $\mathrm{X}$-approximation approach $^{9}$ that produces, inter alia, a definite simplification of the analysis of strongly coupled ${ }^{31} \mathrm{P}$ NMR spectra (see below).

In the present case, the bridging hydrido NMR results from the superposition of three sub-spectra arising from the three different isotopomeric combinations of the platinum nuclei, namely: (i) a central singlet from molecules without ${ }^{195} \mathrm{Pt}$ nuclei $(43.8 \%)$; (ii) a doublet from molecules containing one ${ }^{195} \mathrm{Pt}$ (44.8\%); (iii) a binomial triplet from molecules having two ${ }^{195} \mathrm{Pt}$ $(11.4 \%)$. Therefore, the hydrido NMR spectrum consists of a quintet of approximate relative intensities $1: 8: 18: 8: 1$ (Fig. 1(a)). The fine structure of each line of the three subspectra is determined by ${ }^{31} \mathrm{P}$ couplings. At higher temperature (Fig. 1(b)), each line is split into a quintet indicating the magnetic equivalence of the four $\mathrm{P}$ atoms $\left(\mathrm{A}_{4} \mathrm{Y}\right.$ spin system), consistent with a fast exchange process. At lower temperature (Fig. 1(c)), exchange is hindered and the molecule becomes

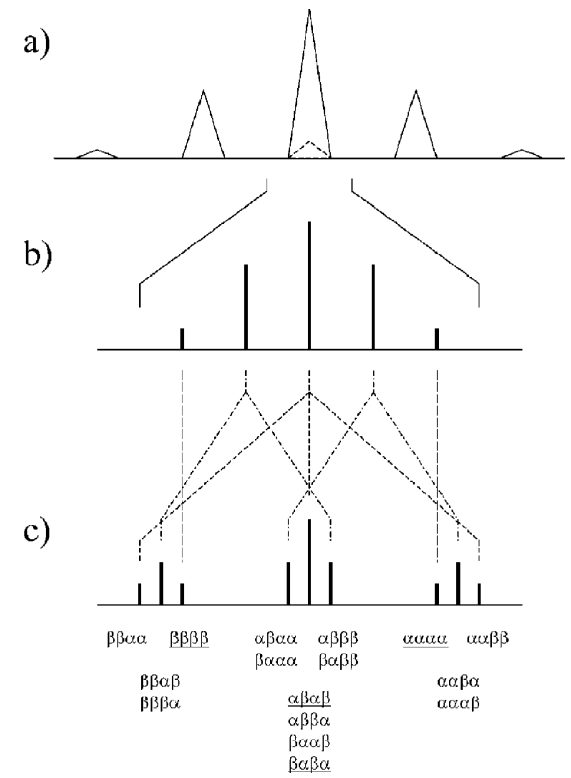

Fig. 1 Sketch of ${ }^{1} \mathrm{H}$ NMR hydrido resonances of complexes 1-3. Arbitrary intensities scale. (a) Low-resolution spectra arising from the three isotopomers. The central line (dashed) of the $1: 2: 1$ triplet from the isotopomer with two ${ }^{195} \mathrm{Pt}$ is superimposed to singlet spectrum. ${ }^{31} \mathrm{P}$ couplings are not resolved. (b) and (c) High-resolution spectra of each line of the spectrum in subpanel (a): at high temperature (b), dynamics is fast and a quintet is observed; at low temperature (c), motion is ineffective on the NMR time scale and a triplet of triplets is observed Variously dashed lines correlate transitions between the low- and hightemperature spectra. The individual ${ }^{1} \mathrm{H}$ NMR transitions within each ${ }^{195} \mathrm{Pt}$ isotopomeric sub-spectrum can be uniquely labelled by the nuclear spin configurations of the four ${ }^{31} \mathrm{P}$ nuclei in the order $\mathrm{P}_{1}, \mathrm{P}_{2}, \mathrm{P}_{3}$ and $\mathrm{P}_{4}$ (see Scheme 1). For instance, $\alpha \alpha \alpha \beta$ refers to the ${ }^{1} \mathrm{H}$ NMR transition where $P_{4}$ is in spin state $\beta$, whereas $P_{1}, P_{2}$ and $P_{3}$ are in spin state $\alpha$. Double underlining denotes the transitions unaffected in both dynamic models, single underlining denotes the transitions unaffected only in the four-site model (see section on dynamical NMR).
Table $1{ }^{1} \mathrm{H}$ NMR data for the hydrido proton in complexes 1-3 in $\mathrm{CD}_{2} \mathrm{Cl}_{2}$ at $300.13 \mathrm{MHz}$. Chemical shift $\delta$ in ppm referenced to TMS and coupling $J$ in Hz. $T_{\text {limit }}(\mathrm{K})$ denotes the temperature of frozen motion of the hydrido ligand. $\hat{J}_{\mathrm{H}-\mathrm{P}}$ is the averaged $\mathrm{H}-\mathrm{P}$ coupling measured at $295 \mathrm{~K}$ for 3, at $311 \mathrm{~K}$ for $\mathbf{2}$ and estimated for 1 at $348 \mathrm{~K}(200.13 \mathrm{MHz}$ in $\left.\mathrm{C}_{2} \mathrm{D}_{2} \mathrm{Cl}_{4}\right)$

\begin{tabular}{lllllll}
\hline Compound & $\delta$ & ${ }^{2} J_{\mathrm{H}-\mathrm{P} \text { cis }}$ & ${ }^{2} J_{\mathrm{H}-\mathrm{P} \text { trans }}$ & ${ }^{1} J_{\mathrm{H}-\mathrm{Pt}}$ & ${ }^{T}$ limit & $\hat{J}_{\mathrm{H}-\mathrm{P}}$ \\
\hline $\mathbf{1}$ & & & & & & \\
$\mathbf{2}$ & -0.83 & -10 & 78.1 & 484 & 186 & $\sim 34$ \\
$\mathbf{3}$ & -1.14 & -12.9 & 76.6 & 454 & 239 & 32.6 \\
\hline
\end{tabular}

rigid so that each line is split into a triplet of triplets consistent with coupling to two pairs of chemically equivalent ${ }^{31} \mathrm{P}$ nuclei ( $\mathrm{AA}^{\prime} \mathrm{XX}^{\prime} \mathrm{Y}$ spin system), namely the two $\mathrm{P}_{c i s}\left(\mathrm{P}_{1}, \mathrm{P}_{2}\right)$ and the two $\mathrm{P}_{\text {trans }}\left(\mathrm{P}_{3}, \mathrm{P}_{4}\right)$ (See Scheme 1 for numbering). The individual ${ }^{1} \mathrm{H}$ NMR transitions within each ${ }^{195} \mathrm{Pt}$ isotopomeric subspectrum can be uniquely labelled by the nuclear spin state of the four ${ }^{31} \mathrm{P}$ nuclei. In the following, we use labels such as $\kappa \lambda \mu \nu$ to denote that $\mathrm{P}_{1}$ is in spin state $\kappa, \mathrm{P}_{2}$ is in spin state $\lambda$, and so on. For instance, $\alpha \alpha \alpha \beta$ refers to the ${ }^{1} \mathrm{H}$ NMR transition where $\mathrm{P}_{4}$ is in spin state $\beta$, whereas $\mathrm{P}_{1}, \mathrm{P}_{2}$ and $\mathrm{P}_{3}$ are in spin state $\alpha$.

The most relevant VT-NMR data for complexes 1-3 are summarised in Table $1\left({ }^{1} \mathrm{H}\right)$ and Table $2\left({ }^{31} \mathrm{P}\left\{{ }^{1} \mathrm{H}\right\}\right.$ and $\left.{ }^{195} \mathrm{Pt}\left\{{ }^{1} \mathrm{H}\right\}\right)$.

\section{${ }^{1}$ H VT-NMR: Hydrido resonances}

The ${ }^{1} \mathrm{H}$ VT-NMR spectra of complexes $\mathbf{1}-\mathbf{3}$ were acquired in normal and ${ }^{31} \mathrm{P}$ decoupled, ${ }^{1} \mathrm{H}\left\{{ }^{31} \mathrm{P}\right\}$, modes in the range 183-313 K, focusing on the bridging hydrido resonance. The static $\left.{ }^{1} \mathrm{H}{ }^{31} \mathrm{P}\right\}$ spectra provided the hydrido chemical shift and the ${ }^{195} \mathrm{Pt}$ connectivity $\left({ }^{1} J_{\mathrm{H}-\mathrm{Pt}}\right)$ and comparison with the corresponding ${ }^{1} \mathrm{H}$ spectra afforded the ${ }^{31} \mathrm{P}$ connectivity $\left({ }^{2} J_{\mathrm{H}-\mathrm{P} \text { trans }}\right.$ and $\left.{ }^{2} J_{\mathrm{H}-\mathrm{P} c i s}\right)$. An illustrative example of this method will be given below for complex 1 (Fig. 2).

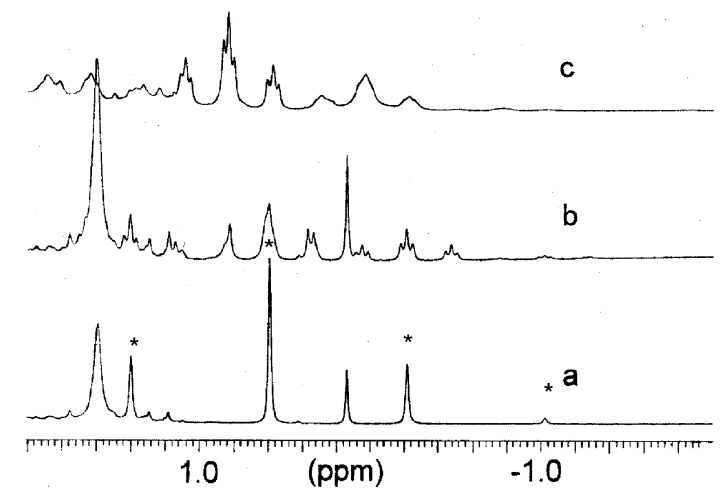

Fig. 2 Selected ${ }^{1} \mathrm{H}$ VT-NMR spectra for the hydrido NMR of complex 1 in $\mathrm{CD}_{2} \mathrm{Cl}_{2}$ at $300.13 \mathrm{MHz}$. Asterisks mark the ${ }^{1} \mathrm{H}-{ }^{195} \mathrm{Pt}$ connectivity. The slight shift of the hydrido patterns are due to a temperature dependence effect. (a) $\left.{ }^{1} \mathrm{H}^{\{1} \mathrm{P}\right\}$ spectrum $(279 \mathrm{~K})$, the quintet pattern due to the $\mathrm{H}-\mathrm{Pt}$ connectivity is centred at $0.6 \mathrm{ppm}, J_{\mathrm{H}-\mathrm{Pt}}$ $=484 \mathrm{~Hz}$. (b) the corresponding ${ }^{1} \mathrm{H}$ spectrum $(279 \mathrm{~K})$ showing the H-P connectivity, the central system $(0.6 \mathrm{ppm})$ is still mobile while frozen motion is observed at the satellite system $\left(-0.2 \mathrm{ppm}, \mathrm{tt},{ }^{2} J_{\mathrm{P} 3(\mathrm{P} 4)}=78.1\right.$ and ${ }^{2} J_{\mathrm{P} 1(\mathrm{P} 2)}=-10 \mathrm{~Hz}$ ). (c) ${ }^{1} \mathrm{H}$ spectrum at $186 \mathrm{~K}$ showing the static limit spectrum for the central system $(0.83 \mathrm{ppm}, \mathrm{tt})$ and some extra broadening on the contiguous satellites.

Table 1 summarises the ${ }^{1} \mathrm{H}$ NMR data relative to static regime along with $T_{\text {limit }}$, the temperature below which no further spectral modification in the hydrido region was observed. The inspection of these data indicates a close similarity between complexes $\mathbf{1}-\mathbf{3}$ both in chemical shift and in $J$-coupling. The chemical shift falls in a narrow range $(-1.66$ to $+0.83 \mathrm{ppm}$ ) depending on the diphosphino ligand as in the parent trihydrido complexes, $\left.\left[\mathrm{Pt}_{2}(\mathrm{P}-\mathrm{P})_{2} \mathrm{H}_{3}\right)\right]^{+} .^{10}$ The low $\mathrm{H}-\mathrm{Pt}$ coupling, from 450 to $484 \mathrm{~Hz}$, is consistent with a hydride 
Table $2{ }^{31} \mathrm{P}$ and ${ }^{195} \mathrm{Pt}$ NMR data for complexes 1-3 in $\mathrm{CD}_{2} \mathrm{Cl}_{2}$ at $121.49\left({ }^{31} \mathrm{P}\right)$ and $64.52\left({ }^{195} \mathrm{Pt}\right) \mathrm{MHz}$, respectively. Chemical shift $\delta$ in ppm referenced to external $85 \% \mathrm{H}_{3} \mathrm{PO}_{4}\left({ }^{31} \mathrm{P}\right)$ and $\mathrm{Na}_{2} \mathrm{PtCl}_{6}\left({ }^{195} \mathrm{Pt}\right) ; J$ coupling $(\mathrm{Hz})$ are from the corresponding ${ }^{31} \mathrm{P}$ spectra

${ }^{31} \mathrm{P}$

${ }^{195} \mathrm{Pt}$

\begin{tabular}{|c|c|c|c|c|c|c|c|c|c|c|}
\hline \multirow[b]{2}{*}{ Compound $(T)^{a}$} & & & & & & & & & & \\
\hline & $\delta_{\mathrm{P} 1(\mathbf{P} 2)}$ & $\delta_{\mathrm{P} 3(\mathbf{P} 4)}$ & ${ }^{2} J_{\mathrm{P} 1-\mathrm{P} 3}$ & ${ }^{3} J_{\mathrm{P} 1-\mathrm{P} 2}$ & ${ }^{3} J_{\mathrm{P} 1-\mathrm{P} 4}$ & $\delta^{b}$ & ${ }^{1} J_{\mathrm{Pt}-\mathrm{P} 1}$ & ${ }^{2} J_{\mathrm{Pt}-\mathrm{P} 1}$ & ${ }^{1} J_{\mathrm{Pt}-\mathrm{P} 3}$ & ${ }^{2} J_{\mathrm{Pt}-\mathrm{P} 3}$ \\
\hline $\mathbf{1}^{c}(186)$ & $\sim 42^{d}$ & $\sim 44^{d}$ & 43.4 & 73.5 & 31.2 & 5507 & $2342^{e}$ & $-182^{e}$ & $4645^{e}$ & $567^{e}$ \\
\hline $2(239)$ & -3.3 & 12.9 & 44.6 & 66.8 & - & 5435 & 2326 & $-182^{f}$ & 4575 & 564 \\
\hline 3 (228) & 11.4 & 21.8 & 44 & 59 & - & 5355 & $\sim 2574^{c}$ & $\sim-184^{c}$ & 4695 & 578 \\
\hline
\end{tabular}

${ }^{a}$ In parentheses, temperature $(\mathrm{K})$ of frozen motion of ${ }^{31} \mathrm{P}$ nuclei $\left(\mathrm{P}_{c i s}-\mathrm{P}_{\text {trans }}\right.$ exchange). ${ }^{b} \delta\left({ }^{195} \mathrm{Pt}\right)$ at $300 \mathrm{~K} .{ }^{c}$ Values estimated on the bases of ${ }^{31} \mathrm{P}$ and ${ }^{195} \mathrm{Pt}$ findings. ${ }^{d}$ The ${ }^{31} \mathrm{P}$ pattern is consistent with an $\mathrm{AA}^{\prime} \mathrm{BB}^{\prime}$ spin system. ${ }^{e}$ From the ${ }^{195} \mathrm{Pt}$ spectrum at $300 \mathrm{~K} .{ }^{f}$ Measured on the ${ }^{195} \mathrm{Pt}$ spectrum at $196 \mathrm{~K}$.

bridging two $\mathrm{PtP}_{2}$ moieties. ${ }^{11}$ The $\mathrm{H}-\mathrm{P}$ couplings, the larger one assigned to $\mathrm{H}-\mathrm{P}_{\text {trans }}$ and the smaller one to $\mathrm{H}-\mathrm{P}_{\text {cis }}$, are in accord with a square planar coordination, according to the reported X-ray crystal structures of $\mathrm{Pt}^{5 b, c}$ and $\mathrm{Pd}^{6 a}$ derivatives. The negative sign of ${ }^{2} J_{\mathrm{H}-\mathrm{P} c i s}$ is obtained from the averaged couplings measured in the fast exchange regime $\left[\hat{J}_{\mathrm{H}-\mathrm{P}}=\left({ }^{2} J_{\mathrm{H}-\mathrm{P} \text { trans }}+\right.\right.$ $\left.\left.{ }^{2} J_{\mathrm{H}-\mathrm{P} \text { c } i s}\right) / 2\right]$, from the dynamical evolution of the spectra, and is also supported by theory. ${ }^{12}$ Conversely, the observed $T_{\text {limit }}$ strongly varies among $\mathbf{1}-\mathbf{3}$ and appears related to the chemical shift difference between $\mathrm{P}_{c i s}$ and $\mathrm{P}_{\text {trans }}$ nuclei (Table 2).

The analysis of the variable temperature ${ }^{1} \mathrm{H}$ spectra shows further analogies among 1-3 and provides preliminary information about the dynamics. In all cases, the static-regime triplet-of-triplets pattern at low temperature translates into a motionally-narrowed quintet pattern at high temperature (see Fig. 1). In the whole temperature range explored: (i) the $\mathrm{H}-\mathrm{Pt}$ couplings remain unaffected, (ii) the $\mathrm{H}-\mathrm{P}$ couplings are maintained and simply averaged, (iii) transitions $\beta \beta \beta \beta$ and $\alpha \alpha \alpha \alpha$ (cf. Fig. 1) are not broadened by the dynamic process. These results point to an intramolecular mutual exchange process.

Due to the spectral quality, the ${ }^{1} \mathrm{H}$ VT-NMR spectra of hydrido region of complexes $\mathbf{2}$ and $\mathbf{3}$ will be discussed in detail by means of dynamic models in the next section, while those of complex 1 are now analysed in a qualitative way.

In spite of the poor resolution, the ${ }^{1} \mathrm{H}$ VT-NMR spectra of complex 1 evidenced some features apparently peculiar in a series of strictly homologous compounds, so that complex $\mathbf{1}$ was examined in a wider temperature range (183-348 K). Unfortunately, the fast exchange limit could not be reached because the complex decomposes at $T>348 \mathrm{~K}$ in solution.

The appearance of the ${ }^{1} \mathrm{H}$ spectra of complexes $\mathbf{1}-\mathbf{3}$ at $300 \mathrm{~K}$ suggests a quasi-static regime for $\mathbf{1}$, slow motion for $\mathbf{2}$ and a fast motional regime for $\mathbf{3}$, hence rigidity increases as $\mathbf{3}<\mathbf{2}<\mathbf{1}$, whereas $T_{\text {limit }}$ follows the order $\mathbf{2}>\mathbf{3}>\mathbf{1}$ (Table 1). This discrepancy results from the behaviour of complex 1 which has the lowest $T_{\text {limit }}(186 \mathrm{~K})$ but displays the slower dynamics at RT.

To facilitate the discussion, selected ${ }^{1} \mathrm{H}$ VT-NMR spectra of complex 1 are shown in Fig. 2. Only the central sub-spectrum and the contiguous upper field satellite $(\delta 0.6$ and -0.22 , respectively, at $279 \mathrm{~K}$ ) could be clearly observed, so that, we limit our analysis to these two sub-spectra. The assignment is unequivocally supported by the ${ }^{1} \mathrm{H}\left\{{ }^{31} \mathrm{P}\right\}$ spectrum (Fig. 2(a)) which shows the quintet pattern due to ${ }^{195} \mathrm{Pt}$ coupling (relative intensities $1: 8: 18: 8: 1$ ) and, in addition, allows one to obtain accurate $\mathrm{Pt}-\mathrm{H}$ couplings. Straightforward comparison with the corresponding ${ }^{1} \mathrm{H}$ spectrum (Fig. 2(b)) highlights the splitting of these lines due to ${ }^{31} \mathrm{P}$ coupling. In this case, the satellite line is split into a well-resolved triplet of triplets while the central subspectrum appears as a broad triplet. Rather surprisingly, an opposite imprint was observed at lower temperature (Fig. 2(c)): a broader triplet and a well-resolved triplet of triplets are found for the satellite and the central sub-spectra, respectively. Considering the whole dynamical range, both sub-spectra follow the typical patterns depicted in Fig. 1. However, the central sub-spectrum reaches the static limit at $186 \mathrm{~K}$ and approaches the expected quintet $\left(\hat{J}_{\mathrm{H}-\mathrm{P}}=34 \mathrm{~Hz}\right)$ at our highest measurement temperature $\left(348 \mathrm{~K}, 200.13 \mathrm{MHz}, \mathrm{C}_{2} \mathrm{D}_{2} \mathrm{Cl}_{4}\right)$. The satellite sub-spectrum is frozen at a definitely higher temperature $(283 \mathrm{~K})$ and the averaged quintet cannot be perceived at $348 \mathrm{~K}$. These unexpected findings seem to indicate that the central and the satellite sub-spectra are differently affected by the exchange dynamics, i.e., that the introduction of ${ }^{195} \mathrm{Pt}$ in complex 1 differentiates the isotopomeric spin systems. However, the various isotopomers should share a common exchange mechanism and have very similar, if not identical, activation parameters since isotopic effects are expected to be small. As for the spin system itself, the data collected in Table 2 show that the major difference between $\mathbf{1}$ and $\mathbf{2}-\mathbf{3}$ is the chemical shift difference between $\mathrm{P}_{\text {cis }}$ and $\mathrm{P}_{\text {trans }}$. The latter is much larger for $\mathbf{2}$ and $\mathbf{3}$ (14.1 and $10.4 \mathrm{ppm}$, respectively) than for $\mathbf{1}$ (ca. $2 \mathrm{ppm}$ ). However, the ${ }^{1} \mathrm{H}$ NMR spectrum is not sensitive to interactions not involving protons such as $\mathrm{P}$ and $\mathrm{Pt}$ chemical shift and Pt-P $J$-coupling

An accurate dynamical line-shape analysis has been carried out for the ${ }^{1} \mathrm{H}$ NMR spectra of complexes $\mathbf{2}$ and $\mathbf{3}$, as mentioned above. The detailed results will be discussed in the next section. The main points for $\mathbf{2}$ and $\mathbf{3}$ are that: the $T_{\text {limit }}$ values are in agreement with the rigidity scale $\mathbf{2}>\mathbf{3}$ based on the ${ }^{1} \mathrm{H}$ spectra at RT; the central sub-spectrum and the satellites reach the static and fast motional regime at equal temperature; an additional selective broadening of some lines of the central sub-spectrum, observable in the intermediate regime and not amenable to the exchange process, needed special treatment.

\section{Dynamical line-shape analysis of hydrido ${ }^{1} \mathrm{H}$ NMR}

The absence of spectral overlap in the hydrido region of the ${ }^{1} \mathrm{H}$ NMR spectra of complexes $\mathbf{2}$ and $\mathbf{3}$ together with the detection of well-resolved spectra throughout the whole dynamical range allowed us to carry out an exhaustive dynamical line-shape analysis which provided detailed results about the exchange processes occurring within such complexes in solution. The analysis is based on the full set of ${ }^{1} \mathrm{H}$ NMR parameters of complexes $\mathbf{2}$ and $\mathbf{3}$ (Table 1), which have been obtained by comparison of ${ }^{1} \mathrm{H}$ with ${ }^{1} \mathrm{H}\left\{{ }^{31} \mathrm{P}\right\}$ NMR spectra, as illustrated in the previous section for complex $\mathbf{1}$.

A detailed theoretical treatment of dynamical NMR spectroscopy in the studied complexes is given in the Computational details section. Here the main points are briefly summarized. The exchange of ${ }^{195} \mathrm{Pt}$ nuclei has no effect on the individual hydrido ${ }^{1} \mathrm{H}$ NMR sub-spectra, so we can restrict our attention to one of the ${ }^{195} \mathrm{Pt}$ sub-spectra (see Fig. 1) and consider a simplified spin system consisting of the observed hydrido proton plus four ${ }^{31} \mathrm{P}$ nuclei, labelled as in Scheme 1. Group theory ${ }^{13}$ reveals that this system may undergo exchange between six sites, all of which have the same NMR spectrum. Sites are interconverted by three types of exchange reactions which unfortunately have not a simple chemical interpretation. For future reference, we note that, within this six-site model, only two ${ }^{1} \mathrm{H}$ NMR lines are not affected by exchange, namely those with spin configuration of the ${ }^{31} \mathrm{P}$ nuclei $\alpha \alpha \alpha \alpha$ and 
$\beta \beta \beta \beta$. Therefore, this model predicts that all but two lines broaden and coalesce due to exchange. However, the six-site model does not agree with the known chemical structure and behaviour of the studied complexes, since it allows exchange between phosphorus nuclei belonging to different ligands. If group-theoretical results are constrained by retaining only chemically-sound structures, we are left with a four-site model where each of the three exchange reaction sets has a well-defined chemical meaning. Set I comprises the trivial identity, i.e., no exchange. Set II consists of the simultaneous exchange of the cis and trans ${ }^{31} \mathrm{P}$ nuclei of both diphosphino ligands or, equivalently, of the hydrido and CO ligands. Set III comprises reactions that exchange the cis and trans phosphorus nuclei of a single diphosphine. We denote the exchange rates of the last two sets as $k_{\mathrm{II}}$ and $k_{\mathrm{III}}$. Within the four-site model, the ${ }^{1} \mathrm{H}$ NMR lines not affected by exchange are those with spin configuration of the ${ }^{31} \mathrm{P}$ nuclei $\alpha \alpha \alpha \alpha$, $\beta \beta \beta \beta, \alpha \beta \alpha \beta$ and $\beta \alpha \beta \alpha$.

The dynamical line shape of the hydride NMR spectra of compounds $\mathbf{2}$ and $\mathbf{3}$ and its temperature dependence are similar. For the sake of conciseness, the variable temperature ${ }^{1} \mathrm{H}$ NMR spectra of complex 3 only are shown in Figs. 3 and 4 along with the fitted line-shapes obtained within the framework of the four- and six-site models.

The ${ }^{195} \mathrm{Pt}$-satellite sub-spectra of the hydrido NMR (see Fig. 3) could be extremely well fitted in the whole temperature range within the four-site model using reaction set III only.

a)

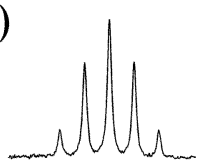

b)

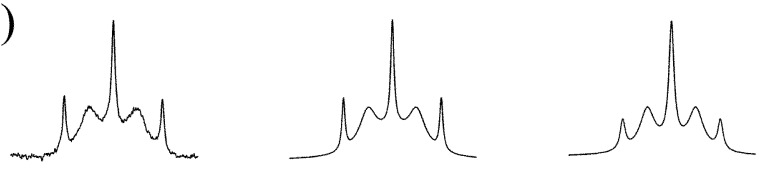

c)

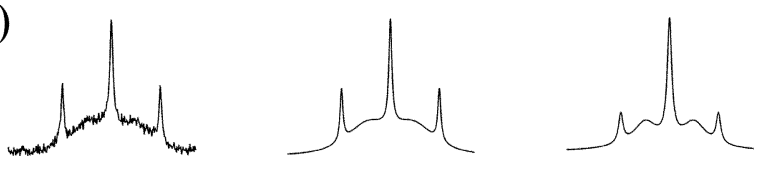

d)

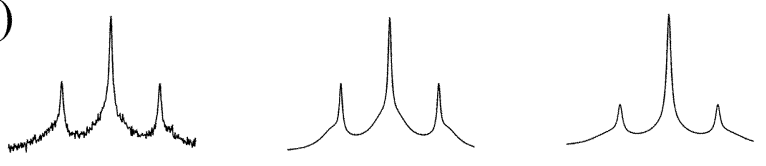

e)

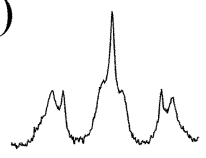

f)
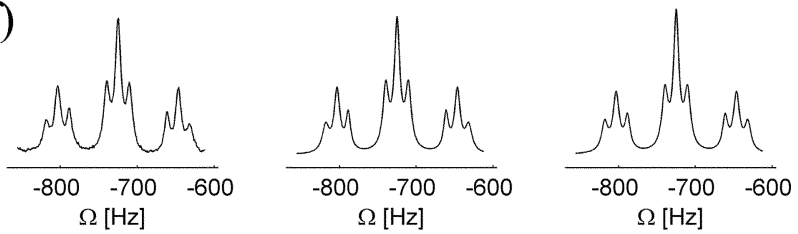

Fig. 3 Selected experimental and fitted hydrido NMR $\left({ }^{195} \mathrm{Pt}\right.$ satellite high-field sub-spectrum) of complex $\mathbf{3}$ as a function of temperature. Temperatures in K: (a) 308, (b) 270, (c) 264, (d) 252, (e) 241, (f) 229 Left: experimental spectra; middle: spectra fitted with the four-site model and $k_{\mathrm{III}}$ only; right: spectra fitted with the four-site model and $k_{\mathrm{II}}$ only. a)
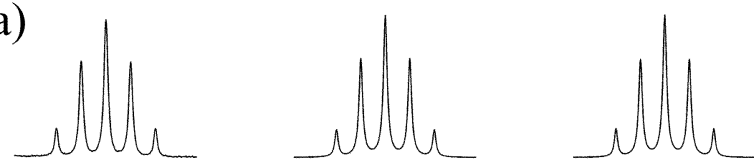

b)
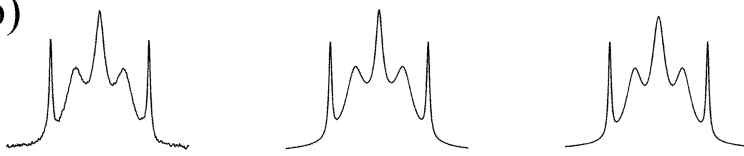

c)
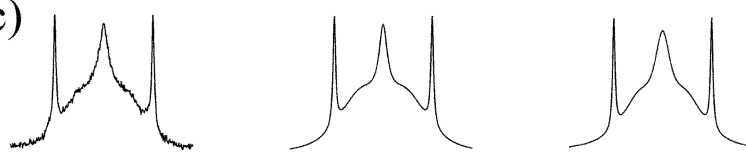

d)
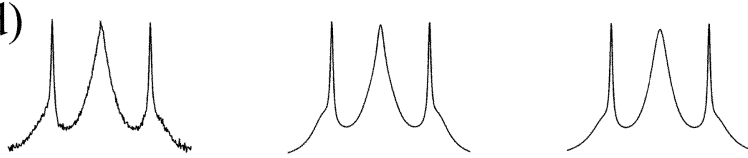

e)
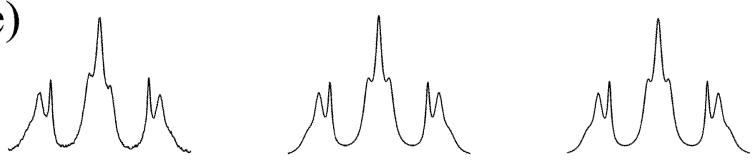

f)
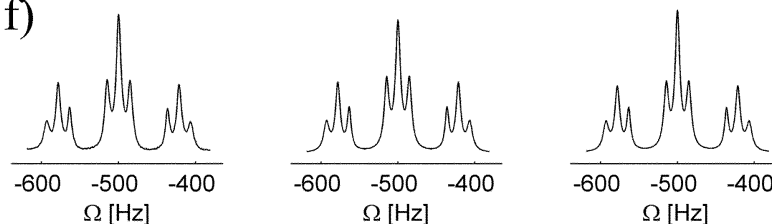

Fig. 4 Selected experimental and fitted hydrido NMR (central subspectrum) of complex 3 as a function of temperature. Temperatures in K: (a) 308, (b) 270, (c) 264, (d) 252, (e) 241, (f) 229. Left: experimental spectra; middle: spectra fitted with the four-site model augmented with off-diagonal cross-relaxation terms and $k_{\text {III }}$ only; right: spectra fitted with the six-site model and both $k_{\text {II }}$ and $k_{\text {III }}$

Reaction set II cannot account for the observed line-shapes as is best appreciated in Fig. 3(b)-(e). The reason is that the central line is not broadened by type II double-exchange so that the amplitude ratio of this line to the other ones is not correct. This can be understood by reference to Fig. 1 as follows. Within the four-site model, the central line is affected by exchange only through the $\alpha \beta \beta \alpha$ and $\beta \alpha \alpha \beta$ spin configurations. Under double exchange these are transformed into each other and hence do not undergo line broadening. Conversely, single exchange transforms the $\alpha \beta \beta \alpha$ and $\beta \alpha \alpha \beta$ configurations into $\beta \beta \alpha \alpha / \alpha \alpha \beta \beta$ and $\alpha \alpha \beta \beta / \beta \beta \alpha \alpha$, respectively, thus causing dynamical broadening (see ESI $\dagger$ for details). Finally, no fit quality improvement is obtained when both sets are used simultaneously. Therefore, ${ }^{31} \mathrm{P}$ exchange in single ligand within the four-site model suffices to fully explain the experimental data. The reaction rates $k_{\text {III }}$ are presented as an Arrhenius plot in Fig. 5. The results of the fit of $k_{\text {III }}$ to Arrhenius and to Eyring law are shown in Table 3. In all cases the linear correlation coefficient is 0.9998 , illustrating the excellent quality of both the line-shape and the Arrhenius/ Eyring fit.

At first, the central (no ${ }^{195} \mathrm{Pt}$ ) sub-spectrum from hydrido NMR (see Fig. 4) did not yield such clear-cut results both for 2 and 3. Indeed, it could not be fitted within the four-site model even with both reaction sets. Using the six-site model with both reaction sets, satisfactory fits could be obtained. However, significant line-shape disagreement can be observed, especially for the central line (see Fig. 4(b)-(d)), and the overall fit quality 
Table 3 Reaction set III activation parameters for complexes $\mathbf{2}$ and $\mathbf{3}$ obtained from fitting $k_{\text {III }}$ to Arrhenius (activation energy $\Delta E^{\ddagger}$, preexponential factor $A$ ) and Eyring (activation enthalpy $\Delta H^{\ddagger}$, activation entropy $\Delta S^{\ddagger}$ ) laws. Linear correlation coefficient $\rho$ is also reported.

\begin{tabular}{|c|c|c|c|c|c|c|}
\hline Compound & Sub-spectrum & $\Delta E^{\ddagger} / \mathrm{kJ} \mathrm{mol}^{-1}$ & $A / 10^{14} \mathrm{~s}^{-1}$ & $\Delta H^{\ddagger} / \mathrm{kJ} \mathrm{mol}^{-1}$ & $\Delta S^{\ddagger} / \mathrm{J} \mathrm{K}^{-1} \mathrm{~mol}^{-1}$ & $\rho$ \\
\hline \multirow[t]{2}{*}{2} & Central $^{a}$ & $69.3 \pm 0.9$ & $1.6 \pm 0.6$ & $67 \pm 1$ & $19 \pm 4$ & 0.9995 \\
\hline & Satellite $^{b}$ & $69.1 \pm 0.6$ & $1.5 \pm 0.4$ & $66.7 \pm 0.6$ & $19 \pm 2$ & 0.9998 \\
\hline \multirow[t]{2}{*}{3} & Central $^{a}$ & $62.4 \pm 0.6$ & $1.2 \pm 0.3$ & $60.3 \pm 0.6$ & $18 \pm 2$ & 0.9997 \\
\hline & Satellite $^{b}$ & $62.2 \pm 0.5$ & $1.1 \pm 0.3$ & $60.0 \pm 0.5$ & $17 \pm 2$ & 0.9998 \\
\hline
\end{tabular}

${ }^{a}$ Line shape fitted to the four-site model augmented with cross-correlation term. ${ }^{b}$ Line shape fitted to the four-site model.

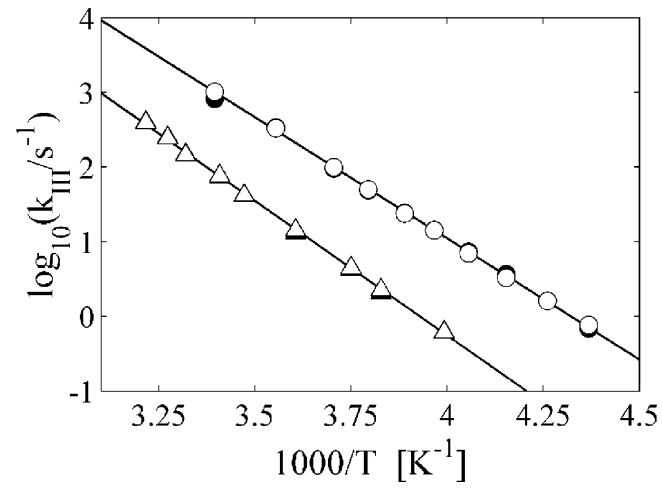

Fig. 5 Arrhenius plot for exchange reaction rate $k_{\text {III }}$ obtained from hydride NMR data. Triangles: 2; circles: 3. Empty symbols: from fitting the ${ }^{195} \mathrm{Pt}$ satellite to the four-site model; filled symbols: from fitting the central sub-spectrum to the augmented four-site model. The regression lines of the two $k_{\mathrm{III}}$ subsets for each compound are actually superimposed in the plot.

is inferior to that obtained in the dynamical analysis of the satellite sub-spectrum (compare Figs. 3 and 4). Moreover, $k_{\text {II }}$ does not follow an activation law (it even has a negative slope for $T>263 \mathrm{~K}$ ) and $k_{\mathrm{III}}$ only roughly does. Even more troublesome is to justify the existence of structures where each diphosphine is ligated to both platinum atoms. These difficulties make the six-site dynamical model highly improbable.

The main difference between the satellite and the central sub-spectra is the intrinsic width of the transitions with ${ }^{31} \mathrm{P}$ spin configuration $\alpha \beta \alpha \beta$ and $\beta \alpha \beta \alpha$, i.e., those not affected by exchange. Therefore, we tried to fit the central sub-spectrum within the four-site model augmented with another free parameter corresponding to cross-relaxation between the above mentioned transitions. As shown in Fig. 4, not only did we obtain excellent line-shape fits at all temperatures, but the qualitative features coincide with those from the dynamical analysis of the satellite sub-spectrum. In particular, ${ }^{31} \mathrm{P}$ singleligand exchange within the augmented four-site model suffices to explain the experimental data; the temperature dependence of $k_{\text {III }}$ almost exactly follows an activation law (see Fig. 5); even more importantly, Arrhenius and Eyring analysis yielded parameters which coincide with those obtained from the satellite sub-spectra within experimental error (see Table 3).

It remains to justify the presence of the cross-correlation term on an a posteriori basis. Surely, the identity of all results from the dynamical analysis of hydride NMR spectroscopy makes the above assumption sound, since exchange phenomena should not be affected by the substitution of ${ }^{195} \mathrm{Pt}$ for nonmagnetic platinum isotopes. Moreover, comparison of the secular and cross-relaxation widths for the central and satellite spectra shows that these parameters have a correct statistical behaviour (see ESI $\dagger$ for details).

In conclusion, the dynamic behaviour of the ${ }^{1} \mathrm{H}$ NMR spectra can be totally ascribed to reaction set III, i.e., to the exchange of the ${ }^{31} \mathrm{P}$ nuclei within a single diphosphine ligand. The process closely follows an activation law with activation enthalpy $\Delta H^{\ddagger}=67$ and $60 \mathrm{~kJ} \mathrm{~mol}^{-1}$ for $\mathbf{2}$ and 3, respectively, so that $\mathrm{P}-\mathrm{Pt}$ bond breaking should not be involved. The broader bite of the diphosphine ligands in 3 decreases $\Delta H^{*}$ by $7 \mathrm{~kJ}$ $\mathrm{mol}^{-1}$. A lower value $\left(\Delta H^{\ddagger}=40 \mathrm{~kJ} \mathrm{~mol}^{-1}\right)$ was obtained ${ }^{14}$ for exchange in the $\mathrm{Pd}(\mathrm{I})$ complex with monodentate phosphine, $\left[\mathrm{Pd}_{2}\left(\mathrm{PPh}_{3}\right)_{4}(\mu-\mathrm{H})(\mu-\mathrm{CO})\right]^{+}$. The positive activation entropy $\left(\Delta S^{\ddagger}=17-19 \mathrm{~J} \mathrm{~K}^{-1} \mathrm{~mol}^{-1}\right)$ hints at a mechanism where the intermediate(s) have structure somehow less ordered than that of the stable complex. On these grounds, a mechanism involving rotation about the Pt-Pt bond could be suggested, such as that pictured in Scheme 2(b).

\section{${ }^{31} \mathbf{P}$ VT-NMR}

The ${ }^{31} \mathrm{P}\left\{{ }^{1} \mathrm{H}\right\}$ VT-NMR measurements (Table 2), together with the above discussed ${ }^{1} \mathrm{H}$ data, confirm that complexes $\mathbf{1}-\mathbf{3}$ belong to the same structural family and support the rigidity scale and the $T_{\text {limit }}$ already established.

The ${ }^{31} \mathrm{P}\left\{{ }^{1} \mathrm{H}\right\}$ static-regime spectra for the complexes $\mathbf{1}-\mathbf{3}$ are shown in Fig. 6. The sub-spectra due to the isotopomer without ${ }^{195} \mathrm{Pt}$ nuclei are consistent with an $\mathrm{AA}^{\prime} \mathrm{BB}^{\prime}(1)$ and an $\mathrm{AA}^{\prime} \mathrm{XX}^{\prime}$ spin system ( $\mathbf{2}$ and $\mathbf{3})$, respectively. These results strongly differentiate $\mathbf{1}$ and account for its peculiar dynamic in the $\mathbf{1}-\mathbf{3}$ series. Since $T_{\text {limit }}$ follows the $\Delta v$ of the exchanging $\mathrm{P}_{1 / 2}$ and $\mathrm{P}_{3 / 4}$ nuclei, $\mathbf{1}$, because of the relatively low $\Delta v$ value (Table 2 ), reaches the slow motion regime at the lowest temperature, in spite of the greatest rigidity. The ${ }^{31} \mathrm{P}\left\{{ }^{1} \mathrm{H}\right\}$ sub-spectra due to the isotopomers with one active ${ }^{195} \mathrm{Pt}\left(\mathrm{AA}^{\prime} \mathrm{XX}^{\prime} \mathrm{M}\right.$ pattern) are in all cases amenable to first order approximation analysis and easily provide the coupling constant values reported in Table 2. Although the intensity of the spectrum due to the third isotopomer is usually too low to be properly analysed, the combination transitions due to $\left({ }^{1} J+{ }^{2} J\right)_{\mathrm{P} 3 / 4-\mathrm{Pt}}$ and $\left({ }^{1} J+{ }^{2} J\right)_{\mathrm{P} 1 / 2-\mathrm{Pt}}$ can be easily observed and the relative sign of the involved couplings assigned. Due to the strongly different trans-influence between the bridging ligands $(\mu-\mathrm{CO} \gg \mu-\mathrm{H})$, two well distinct

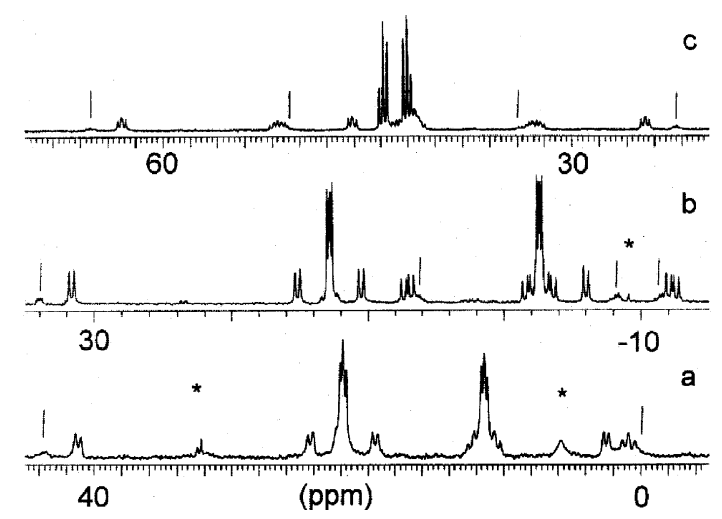

Fig. $6{ }^{31} \mathrm{P}$ NMR spectra for complexes 1-3 in the static regime for $\mathrm{P}_{c i s}$ $\mathrm{P}_{\text {trans }}$ exchange in $\mathrm{CD}_{2} \mathrm{Cl}_{2}$ at $121.49 \mathrm{MHz}$. (a) Complex 3 at $228 \mathrm{~K}$, (b) complex 2 at $239 \mathrm{~K}$, (c) complex 1 at $186 \mathrm{~K}$. The sub-spectra of the isotopomer without ${ }^{195} \mathrm{Pt}$ show an $\mathrm{AA}^{\prime} \mathrm{XX}^{\prime}$ pattern (2 and 3) or an $\mathrm{AA}^{\prime} \mathrm{BB}^{\prime}$ pattern (1). The satellite sub-spectra for the isotopomer with one ${ }^{195} \mathrm{Pt}$ are first order with respect to the ${ }^{31} \mathrm{P} J$ coupling and provide most of the data in Table 2. Asterisks denote impurity peaks while the vertical segments denote the combination transitions $\left({ }^{1} J+{ }^{2} J\right)_{\mathrm{P} 3}$ and $\left({ }^{1} J+{ }^{2} J\right)_{\mathrm{P} 1}$ belonging to the isotopomeric sub-spectra with two ${ }^{195} \mathrm{Pt}$. For 2 (b) all the expected transitions are detected, for $\mathbf{1}$ (c) and for $\mathbf{3}$ (a) severe overlapping is observed. 


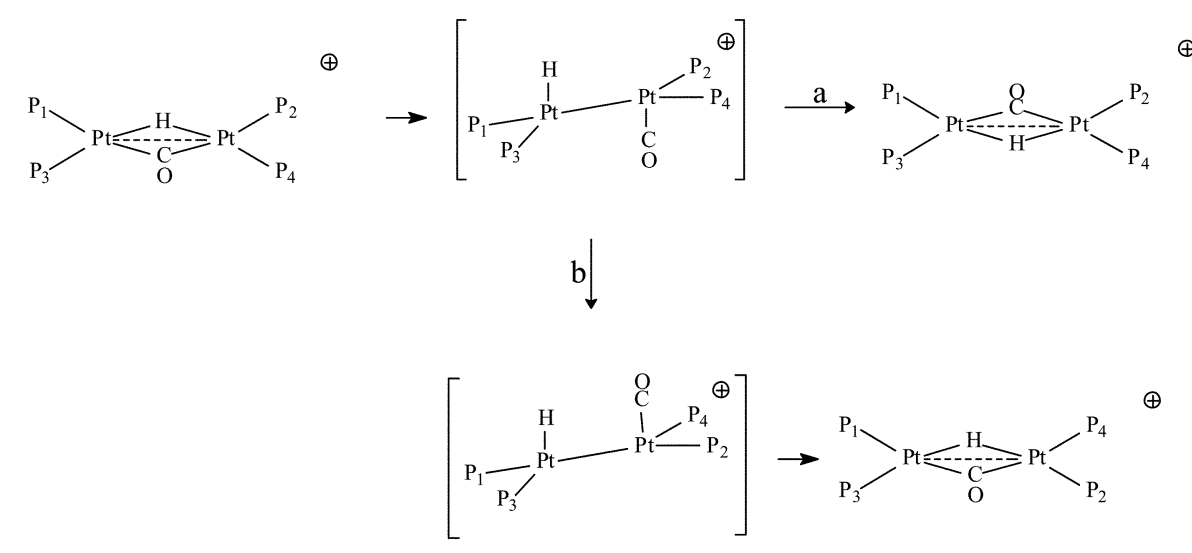

a) Reaction set II: simultaneous $1 \rightleftharpoons 3,2 \rightleftharpoons 4$

b) Reaction set III: rotation around Pt-Pt axis; $1=3$ or $2=4$ at onœ

Scheme 2 Schematic picture of the exchange paths for complexes 1-3.

sets of ${ }^{1} J_{\mathrm{P}-\mathrm{Pt}}$ values $\left({ }^{1} J_{\mathrm{P} 1 / 2-\mathrm{Pt}} \ll{ }^{1} J_{\mathrm{P} 3 / 4-\mathrm{Pt}}\right)$ characterise the two $\mathrm{P}$ binding sites and allow the definite assignment for $\mathrm{P}_{1 / 2}$ and $\mathrm{P}_{3 / 4}$ as trans-CO and trans- $\mathrm{H}$, respectively. The differences between the two binding sites as well as among the different ring sizes (five-, 1, six-, 2 and seven-, 3, membered rings) are mirrored in the chemical shift differences, either in each of these cations $\left(\mathrm{P}_{\text {cis }}<\mathrm{P}_{\text {trans }}\right)$ and within the 1-3 series. According to the different strain of the (P-P)Pt cycles, which implies different $\Delta_{\mathrm{R}}$ contributions, ${ }^{15}$ the observed deshielding with respect to the free ligands of both $\mathrm{P}$ donors $\left(\mathrm{P}_{\text {cis }}\right.$ and $\left.\mathrm{P}_{\text {trans }}\right)$ is smaller for $\mathbf{3}$ and $\mathbf{2}$ than for $\mathbf{1}$ and possibly explains the observed differences.

The dependence of the chemical shift difference between the two binding sites on the opposite ligand and on the chelating diphosphine observed in each of the species 1-3 $\left(\mathrm{P}_{c i s}<\mathrm{P}_{\text {trans }}\right)$ can better be considered in terms of the quantity $\Delta \delta=\delta_{(\mathrm{H} 3)}$ $\delta_{(\mathrm{H}, \mathrm{CO})}$, that is the chemical shift difference between the complex and the corresponding trihydride, $\left[\mathrm{Pt}_{2}(\mathrm{P}-\mathrm{P})_{2}(\mathrm{H})_{3}\right]^{+},{ }^{10}$ i.e., the precursors of cations 1-3. On this basis, we observe that the trans-CO $\mathrm{P}_{1 / 2}$ is significantly shifted at higher field in the sequence $\mathbf{1}>\mathbf{2}>\mathbf{3}(\Delta \delta=14.4,12.3$ and 11.5, respectively). At variance the trans-H $\mathrm{P}_{3 / 4}$ is slightly affected in the cases of complexes $\mathbf{2}(\Delta \delta=-3.9)$ and $\mathbf{3}(\Delta \delta=1.1)$ but is strongly displaced at higher fields for complex $\mathbf{1}(\Delta \delta=13.5)$, so that cation 1 could appear anomalous. However, the same trend is observed in similar platinum hydrides bearing different $\mathrm{C}$-bridged ligands, such as the $\mu$-isocyanide $\left[\mathrm{Pt}_{2}(\mathrm{P}-\mathrm{P})_{2}(\mu-\mathrm{H})(\mu-\mathrm{CNR})\right]^{+},{ }^{5 a, b}$ or the $\mu$-alkylidene $\left[\mathrm{Pt}_{2}(\mathrm{P}-\mathrm{P})_{2}(\mu-\mathrm{H})\left(\mu-\mathrm{CHCH}_{2} \mathrm{R}\right)\right]^{+16}$ compounds. Moreover, the cation $\left[\mathrm{Pt}_{2}(\mathrm{dcype})_{2}(\mu-\mathrm{H})(\mu-\mathrm{CO})\right]^{+}$, i.e. the homologous of $\mathbf{3}$ with aliphatic substituents, behaves analogously: the $\mathbf{P}_{\text {cis }}$ and $\mathrm{P}_{\text {trans }}$ signals are nearly overlapped and largely displaced with respect to the signal of the hydrido precursor $(\Delta \delta: 19.0){ }^{5 d}$ This suggests that the effect of the opposite ligand on the $\mathrm{P}$ shift is significant with strong donors such as $\mathrm{CO}$, whereas with the simplest ligand hydride, the dominant role is played by the size of the chelating ring. Finally, we observe that the ${ }^{3} J_{\mathrm{P} 1-\mathrm{P} 2}$ values increase upon decrease of the $(\mathrm{P}-\mathrm{P}) \mathrm{Pt}$ ring sizes. The influence of the ring sizes on the electronic distribution in the inner core of binuclear platinum hydrides was previously outlined by Tulip et al. who observed an increase of the $\mathrm{s}$ character of $\mathrm{Pt}$ orbital bonding upon decrease of the ring size. ${ }^{17}$

A further dynamic process has been observed in complex $\mathbf{3}$ at temperatures below $T_{\text {limit }}(228 \mathrm{~K})$. The lower resolution of the slow exchange spectrum of $\mathbf{3}$ (Fig. 6) together with the additional broadening observed by further lowering the temperature, led us to presume the presence of motion at $228 \mathrm{~K}$ and the onset of a new process at lower temperature. The system was monitored by ${ }^{31} \mathrm{P}$ (see ESI $\dagger$ ) and ${ }^{1} \mathrm{H}$ NMR from 228 to 175 $\mathrm{K}$, where the solution freezes. The ${ }^{31} \mathrm{P}$ spectra remain rather broad down to $175 \mathrm{~K}$, and do not provide significant insight, apart from indicating the presence of a low activation energy process. A valuable hint was instead given by the ${ }^{1} \mathrm{H}$ results. Even if no significant variation occurred in the hydrido region throughout the studied temperature range, at $T<209 \mathrm{~K}$ the apparent degeneracy of the signals due to the $\mathrm{CH}_{2}$ protons next to the $\mathrm{P}$ atom was raised and a splitting of these transitions observed. Besides, a similar experiment performed on complex 2 led to analogous results for $T<196 \mathrm{~K}$. These findings rule out any exchange of $\mathbf{P}_{c i s}$ and $\mathbf{P}_{\text {trans }}$, rather they hint at a slowing down of phosphine side-chain conformational motion.

\section{Diphosphine exchange experiments}

Although all evidences so far obtained indicate that the $\mathbf{P}_{c i s}-\mathbf{P}_{\text {trans }}$ equilibration occurs via an intramolecular process, two reactivity experiments were carried out to exclude pathways involving $\mathrm{P}-\mathrm{Pt}$ and/or $\mathrm{Pt}-\mathrm{Pt}$ bond breaking. It is worth mentioning that $\mathrm{Pd}(\mathrm{I})$ hydrido-carbonyl cations originate from mononuclear species through acceptor-donor mechanisms ${ }^{6,7,14}$ and that, even if rather uncommon, scrambling of chelating diphosphines has been observed in mononuclear ${ }^{18}$ and binuclear ${ }^{19}$ platinum(II) hydrides.

In the first experiment, performed in a NMR tube at $195 \mathrm{~K}$, a stoichiometric amount of dppe ligand was added to a solution of complex 3 in $\mathrm{CD}_{2} \mathrm{Cl}_{2}$ and the evolution of the mixture monitored by ${ }^{1} \mathrm{H}$ and ${ }^{31} \mathrm{P}\left\{{ }^{1} \mathrm{H}\right\}$ NMR spectroscopy at different temperatures and times. The resonances of complex 3 disappeared almost immediately giving rise to a complex mixture of platinum-containing species. At variance from analogous experiments carried out on the Pd derivatives, ${ }^{7}$ no resonance from hydrido complexes was observed. Hence, the binuclear hydrido carbonyl species was irreversibly disrupted and no species strictly related to the precursor of molecular core was detected.

In a further experiment, a mixture of complexes $\mathbf{1}$ and $\mathbf{3}$ in $\mathrm{CD}_{2} \mathrm{Cl}_{2}$ was prepared and monitored by VT-NMR spectroscopy over several days. Just after mixing, both $\mathbf{1}$ and $\mathbf{3}$ displayed the dynamic behaviour previously observed, and no 
reaction between the two complexes was detected. Indeed, both ${ }^{1} \mathrm{H}$ and ${ }^{31} \mathrm{P}\left\{{ }^{1} \mathrm{H}\right\}$ NMR spectra of the mixture were the exact superposition of the spectra of species $\mathbf{1}$ and 3, even after long standing (20 days) in solution. Moreover a ${ }^{31} \mathrm{P} 2 \mathrm{D}-\mathrm{NMR}$ chemical exchange experiment (500 ms mixing time, $273 \mathrm{~K}$ ) performed on this mixture, after $2 \mathrm{~h}$ standing at RT, showed the expected correlations within each complex (amenable to $\mathrm{P}_{c i s}$ $\mathrm{P}_{\text {trans }}$ exchange) and excluded cross interaction between different species. An analogous result was obtained in a similar experiment ( $100 \mathrm{~ms}$ mixing time, $300 \mathrm{~K})$ performed on this sample after $8 \mathrm{~h}$ standing at RT.

In conclusion, these reactivity experiments provide further support to intramolecular dynamics and exclude any equilibration path involving $\mathrm{Pt}-\mathrm{P}$ and/or $\mathrm{Pt}-\mathrm{Pt}$ bond breaking.

\section{${ }^{195}$ Pt VT-NMR}

${ }^{195} \mathrm{Pt}$ NMR spectroscopy confirmed the overall picture about complexes 1-3. The analysis of the spin system and of the experimental results refer to the isotopomer with a single magnetic nucleus, since the lines due to isotopomers with two ${ }^{195} \mathrm{Pt}$ are very weak. In the static regime, the magnetic Pt nucleus is coupled, in addition to the hydrido proton, to four phosphorus atoms $\mathrm{P}_{3}, \mathrm{P}_{1}, \mathrm{P}_{4}$ and $\mathrm{P}_{2}$ (ordered on the basis of $J$ magnitude) resulting in 16 transitions (labelled as in the ESI $\dagger$ ) for each hydrido proton spin state. Accordingly, the $300 \mathrm{~K}$ spectrum of 1 , in static regime, consists of an $\mathrm{AA}^{\prime} \mathrm{XX}^{\prime} \mathrm{M}$ spin system and displays the expected 16-line pattern, (Fig. 7). In the intermediate exchange regime, the experimental findings for complex 2 (Fig. 7) display the unaffected spectral lines with ${ }^{31} \mathrm{P}$ nuclear spin configurations $\beta \beta \beta \beta, \beta \beta \alpha \alpha, \alpha \alpha \beta \beta, \alpha \alpha \alpha \alpha$. This result is perfectly consistent with the mechanistic hypothesis formulated and with the coupling values of Table 2, in particular with a negative sign for ${ }^{2} J_{\mathrm{Pt}-\mathrm{P} 1}$. Last, the evolution of the spectral pattern to the fast exchange limit $\left(\mathrm{A}_{2} \mathrm{X}_{2} \mathrm{M}\right.$ spin system $)$ is expected to produce a triplet of triplets centred at $\delta_{\mathrm{Pt}}$ with a large coupling $J=\left({ }^{1} J_{\mathrm{Pt}-\mathrm{P} 1}+{ }^{1} J_{\mathrm{Pt}-\mathrm{P} 3}\right) / 2$ and a small one $J=\left({ }^{2} J_{\mathrm{Pt}-\mathrm{P} 2}\right.$ $\left.+{ }^{2} J_{\mathrm{Pt}-\mathrm{P} 4}\right) / 2$ being the $\beta \beta \beta \beta$ and $\alpha \alpha \alpha \alpha$ transitions the outside lines of the spectrum. Again, our NMR findings agree with this picture. Although none of complexes 1-3 has reached in our experimental range (193-300 K) such a fast exchange limit, the ${ }^{195} \mathrm{Pt}$ spectrum of 3 , measured at $42.8 \mathrm{MHz}$ and $300 \mathrm{~K}$, clearly evidences the incoming new lines between the transitions $(\beta \beta \beta \beta$, $\beta \beta \alpha \alpha)$ and $(\alpha \alpha \beta \beta, \alpha \alpha \alpha \alpha)$ and a triplet emerging at the centre of the system.
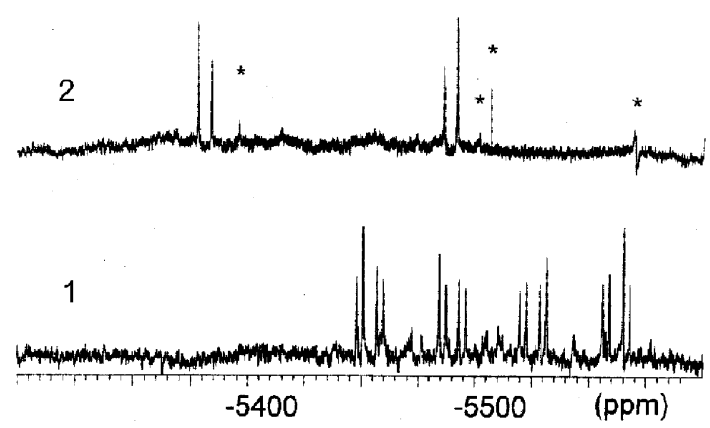

Fig. $7{ }^{195} \mathrm{Pt}$ NMR spectra for complexes 1 and 2 in $\mathrm{CD}_{2} \mathrm{Cl}_{2}, 64.52$ $\mathrm{MHz}, 300 \mathrm{~K}$. Chemical shifts in ppm referenced to external $\mathrm{Na}_{2} \mathrm{PtCl}_{6}$. Asterisks mark impurity peaks or spikes. The spectrum of $\mathbf{1}$ (static regime) shows 16 transitions due to Pt-P couplings while the spectrum of 2 (dynamical regime) displays the four unaffected transitions throughout the temperature range.

\section{Conclusions}

VT-NMR spectroscopy of all of the magnetic nuclei $\left({ }^{1} \mathrm{H},{ }^{31} \mathrm{P}\right.$ and ${ }^{195} \mathrm{Pt}$ ) provided a detailed description of the spin system on complexes 1-3. Many spin Hamiltonian parameters have been accurately determined and the dynamical line-shape analysis revealed that the main dynamical process is the exchange of the two $\mathrm{P}$ nuclei belonging to a single diphosphino ligand. Accurate exchange activation parameters have been obtained. Unfortunately, NMR spectroscopy resulted to be in itself unable to give an unquestionable picture of the chemical mechanism underlying the ${ }^{31} \mathrm{P}$ exchange dynamics of $\left[\mathrm{M}_{2}-\right.$ $\left.(\mathrm{P}-\mathrm{P})_{2}(\mu-\mathrm{H})(\mu-\mathrm{CO})\right]^{+}$complexes, because of the high molecular symmetry or the possible presence of intermediates elusive on the NMR time scale. Besides, the activation parameters are not in disagreement with the literature suggestions on the possible mechanisms ${ }^{5 b, 7,14}$ However, some conclusions can be drawn by considering the whole of reactivity, structure, and spectroscopic data reported for these cations.

The following points can be emphasized: (i) the dynamic process is intramolecular, requires low activation enthalpy $\left(\Delta H^{*}=60 \div 67 \mathrm{~kJ} \mathrm{~mol}^{-1}\right)$ and shows slightly positive entropy values $\left(\Delta S^{\ddagger}=17-19 \mathrm{~J} \mathrm{~K}^{-1} \mathrm{~mol}^{-1}\right)$; (ii) all compounds are diamagnetic at any temperature; (iii) the binuclear structure is unaffected in solution; (iv) both bridging ligands undergo exchange reactions, such as $\mathrm{D} / \mathrm{H},{ }^{6 b}{ }^{13} \mathrm{CO} / \mathrm{CO},{ }^{7}$ and $\mathrm{RNC} / \mathrm{CO} ;{ }^{5 a, b}$ (v) all compounds originated mononuclear species only by reaction with strong coordinating reactants, ${ }^{6 b, 8}$ (vi) in the vapour phase, complexes 1-3 easily lose HCO while maintaining the bimetallic structure in all of the primary decomposition pathways; ${ }^{20}$ (vii) the $\mathrm{M}-\mathrm{M}$ distances established in the solid state (from $115 \mathrm{~K}$ to room temperature) are very short.

A mechanism involving the geometrical rearrangement on both metal centres was not excluded a priori ${ }^{7}$ but was overshadowed by the observed bridge-splitting reactions (iv) that led to suggest an equilibration process via rotation around a $\mathrm{M}-\mathrm{X}-\mathrm{M}$ bond $(\mathrm{X}=\mathrm{CO}$ or $\mathrm{H})$ in the two equally possible mono-bridged tautomers. However, this route implicitly requires the $\mathrm{M}-\mathrm{M}$ cleavage to equilibrate the four $\mathrm{P}$ atoms. The occurrence of bridge-splitting processes is of course out of the question, and $\mathrm{M}-\mathrm{M}$ bond breaking does not seem reasonable. In fact, leaving out sophisticated explanations for the diamagnetic behaviour, points (iii)-(vii) provide compelling evidence about the strength of the $\mathrm{M}-\mathrm{M}$ bond. For instance, the fragmentation pattern of cations $\mathbf{1}-\mathbf{3}$ in the vapour phase (vi) indicates that the $\mathrm{M}-\mathrm{M}$ bond is the strongest bond in the molecular core. The kinetic energy release values associated to the easy loss of HCO are lower by one order of magnitude than those calculated for the $3 \mathrm{H}$ loss from the corresponding trihydrido precursors, $\left[\mathrm{Pt}_{2}(\mathrm{P}-\mathrm{P})_{2}(\mathrm{H})_{3}\right]^{+}{ }^{20}$ From a different point of view, and in addition to analogous substitution products (iv), the substitution of the bridging carbonyl with a sterically demanding isocyanide in solution gave the complex $[(\mathrm{H})$ $(\mathrm{P}-\mathrm{P}) \mathrm{Pt}-\mathrm{Pt}(\mathrm{P}-\mathrm{P})(\mathrm{CNR})]^{+}\left(\mathrm{P}-\mathrm{P}=\mathrm{dppe} ; \mathrm{R}=\left(\mathrm{CH}_{3}\right){ }_{3} \mathrm{CNC}\right),{ }^{5 b} \mathbf{4}$, bearing only terminal ligands, which can be considered as the effective intermediate in substitution reactions.

All these considerations strengthen the hypothesis that the equilibration process of the cations $\mathbf{1}-\mathbf{3}$ occurs by rotation around the $\mathrm{M}-\mathrm{M}$ bond, as illustrated in Scheme 2, i.e. through a tautomer in which both $\mathrm{H}$ and $\mathrm{CO}$ ligands are terminally bonded as in the above mentioned complex 4 . Indeed, easy rotation of two $(\mathrm{P}-\mathrm{P}) \mathrm{Pt}$ moieties around the $\mathrm{Pt}-\mathrm{Pt}$ bond has recently been observed in the polymorphic $\mathrm{Pt}(\mathrm{I})$ hydride $\left[\mathrm{Pt}_{2}(\mathrm{dfepe})_{2}(\mathrm{H})_{2}\right]$ in the solid state. ${ }^{21}$

\section{Experimental}

\section{NMR measurements}

The NMR spectra were recorded on Bruker AC $200\left({ }^{1} \mathrm{H}\right.$ at $200.13 \mathrm{MHz},{ }^{31} \mathrm{P}$ at $81.02 \mathrm{MHz}$ and ${ }^{195} \mathrm{Pt}$ at $50.32 \mathrm{MHz}$ ) and Bruker Avance DRX-300 $\left({ }^{1} \mathrm{H}\right.$ at $300.13 \mathrm{MHz},{ }^{31} \mathrm{P}$ at 121.49 $\mathrm{MHz}$ and ${ }^{195} \mathrm{Pt}$ at $64.52 \mathrm{MHz}$ ) spectrometers with $5 \mathrm{~mm}$ Inverse probe, by using standard pulse sequences from the Bruker library. The chemical shifts $(\delta)$ are referenced to TMS $\left({ }^{1} \mathrm{H}\right)$, external $85 \% \mathrm{H}_{3} \mathrm{PO}_{4}\left({ }^{31} \mathrm{P}\right)$ and $\mathrm{Na}_{2} \mathrm{PtCl}_{6}\left({ }^{195} \mathrm{Pt}\right)$. The spectra of all nuclei (except ${ }^{1} \mathrm{H}$ ) were ${ }^{1} \mathrm{H}$ decoupled. The ${ }^{1} \mathrm{H}$ spectra were 
acquired in normal and ${ }^{31} \mathrm{P}$ decoupled mode in the whole temperature range explored.

2D ${ }^{31} \mathrm{P}$-Chemical exchange spectra were acquired by the method of Bodenhausen et al. ${ }^{22}$ using 1024 data points in $t_{2}$ for $128 t_{1}$ values and a pulse repetition delay of $1.5 \mathrm{~s}$ for mixing times ranging from 100 to $500 \mathrm{~ms}$. 2D NMR data sets were zero-filled to 512 points in the $t_{1}$ dimension and apodised with a shifted sinebell function.

All temperatures $(\mathrm{K})$ were calibrated with $4 \%$ methanol in methanol- $d_{4}$ (range $300-180 \mathrm{~K}$ ) and $80 \%$ ethylene glycol in DMSO- $d_{6}$ (range $380-300 \mathrm{~K}$ ) by measuring the frequency difference between the $\mathrm{OH}$ and the $\mathrm{CH}_{3}$ (methanol) or $\mathrm{CH}_{2}$ (glycol) signals.

\section{Preparation of compounds 1-3}

Complexes 1-3 were obtained and purified according to literature methods. ${ }^{5 b}$ The $\mathrm{CD}_{2} \mathrm{Cl}_{2}$ solutions for the NMR measurements were in the range $0.04-0.01 \mathrm{M}$.

\section{Reaction of $\left[\mathrm{Pt}_{2}(\mathrm{dppb})_{2}(\mu-\mathrm{H})(\mu-\mathrm{CO})\right]^{+}(3)$ and dppe}

All manipulations were carried out at $195 \mathrm{~K}$ under a purified $\mathrm{N}_{2}$ atmosphere by using standard Schlenk techniques. $7.8 \mathrm{mg}$ of dppe $(19.6 \mu \mathrm{mol})$ was dissolved in $0.5 \mathrm{ml}$ of $\mathrm{CD}_{2} \mathrm{Cl}_{2}$ and added to a violet solution of $3\left(25 \mathrm{mg}, 19.7 \mu \mathrm{mol}\right.$ in $\left.0.5 \mathrm{ml} \mathrm{CD}_{2} \mathrm{Cl}_{2}\right)$ into an NMR tube. The resulting mixture, which immediately turned yellow, was transferred into the spectrometer probe, pre-cooled at $195 \mathrm{~K}$ for ${ }^{1} \mathrm{H}$ and ${ }^{31} \mathrm{P}$ measurements. The NMR spectra were acquired each $30 \mathrm{~min}$ alternating ${ }^{1} \mathrm{H}$ and ${ }^{31} \mathrm{P}$ observation and raising the temperature, in $10 \mathrm{~K}$ steps, from 193 to $273 \mathrm{~K}$. The sample was then stored at $253 \mathrm{~K}$ and measured again, after 7 days, in the 300-203 K range.

\section{Mixture of $\left[\mathrm{Pt}_{2}(\mathrm{dppb})_{2}(\mu-\mathrm{H})(\mu-\mathrm{CO})\right]^{+}(3)$ and $\left[\mathrm{Pt}_{2}(\mathrm{dppe})_{2}(\mu-\mathrm{H})-\right.$ $(\boldsymbol{\mu}-\mathbf{C O})]^{+}(\mathbf{1})$}

The preparation of this sample was performed directly into a NMR tube at room temperature. $0.5 \mathrm{ml}$ of solution of $1(0.039$ $\mathrm{M}$ in $\left.\mathrm{CD}_{2} \mathrm{Cl}_{2}\right)$ and of $3\left(0.041 \mathrm{M}\right.$ in $\left.\mathrm{CD}_{2} \mathrm{Cl}_{2}\right)$ were mixed and the resulting solution was inserted into the spectrometer probe. The ${ }^{1} \mathrm{H}$ and ${ }^{31} \mathrm{P}$ NMR spectra were recorded at $300 \mathrm{~K}$ immediately after the preparation and after $2 \mathrm{~h}$ standing at the same temperature. The VT measurements were performed in the range 213-300 K. 2D ${ }^{31} \mathrm{P}$-Chemical exchange spectra were acquired at 273 and $300 \mathrm{~K}$. The sample was stored at low temperature and reanalysed after 5 days at $300 \mathrm{~K}$ (in ${ }^{1} \mathrm{H}$ observation, 500.13 $\mathrm{MHz}$ ) and after 20 days (in ${ }^{1} \mathrm{H},{ }^{1} \mathrm{H}\left\{{ }^{31} \mathrm{P}\right\}$ and ${ }^{195} \mathrm{Pt}$ observations).

\section{Dynamical NMR theory and computation}

First, we analyse the symmetry properties of that part of the spin Hamiltonian that determines the frequency of hydrido ${ }^{1} \mathrm{H}$ NMR spin transitions by group-theoretical methods. Denoting the phosphorus nuclear sites with index $i=1,2,3,4$ (see Scheme 1) and noting that exchange of ${ }^{195} \mathrm{Pt}$ ions has no effect on the individual hydrido NMR sub-spectrum, we can write a restricted spin Hamiltonian suited to our goal as (in frequency units):

$$
\begin{aligned}
& \frac{\hat{H}}{\hbar}=\omega_{0}^{\mathrm{H}} I_{z}^{\mathrm{H}}+ \sum_{i} J_{\mathrm{P}_{i}-\mathrm{H}} I_{z}^{\mathrm{H}} I_{z}^{\mathrm{P}_{i}}= \\
& I_{z}^{\mathrm{H}}\left[\omega_{0}^{\mathrm{H}}+J_{\mathrm{H}-\mathrm{P} c i s}\left(I_{z}^{\mathrm{P}_{1}}+I_{z}^{\mathrm{P}_{2}}\right)+J_{\mathrm{H}-\text { Prans }}\left(I_{z}^{\mathrm{P}_{3}}+I_{z}^{\mathrm{P}_{4}}\right)\right]
\end{aligned}
$$

where $\omega_{0}^{\mathrm{H}}$ is the chemically shifted Larmor frequency of the proton, $J_{\mathbf{P}_{-} \mathrm{H}}=J_{\mathrm{H}-\mathrm{P} c i s}$ for phosphorus sites $i=1,2$ and $J_{\mathbf{P}_{i}-\mathrm{H}}=$ $J_{\mathrm{H}-\mathrm{P} \text { trans }}$ for phosphorus sites $i=3,4$.

Clearly, this spin Hamiltonian is invariant under the permutations (1)(2)(3)(4) = identity, (12)(34), (12)(3)(4) and (1)(2)(34) Because of these symmetry properties the 24 possible nuclear
Table 4 Classification of the nuclear configurations according to the symmetry of the spin Hamiltonian. The reference configuration shown in Scheme 1 is denoted by 1234. For instance, configuration 3214 means that phosphorus spin 1 is in location 3 , phosphorus spin 2 is in location 2 , and so on. The canonical configurations (in bold face) form subclasses $\mathrm{A}^{\prime}, \mathrm{B}^{\prime}, \mathrm{E}^{\prime}$ and $\mathrm{F}^{\prime}$

\begin{tabular}{lllll}
\hline Class & $u_{1}$ & $u_{2}$ & $u_{3}$ & $u_{4}$ \\
\hline A & $\mathbf{1 2 3 4}$ & $\mathbf{2 1 4 3}$ & 2134 & 1243 \\
B & $\mathbf{3 2 1 4}$ & $\mathbf{2 3 4 1}$ & 2314 & 3241 \\
C & 4231 & 2413 & 2431 & 4213 \\
D & 1324 & 3142 & 3124 & 1342 \\
E & $\mathbf{1 4 3 2}$ & $\mathbf{4 1 2 3}$ & 4132 & 1423 \\
F & $\mathbf{3 4 1 2}$ & $\mathbf{4 3 2 1}$ & 4312 & 3421 \\
\hline
\end{tabular}

configurations of the complexes correspond to only six unique spin Hamiltonians. Therefore, the 24 nuclear configurations can be grouped into six equivalence classes $(\mathrm{A}, \mathrm{B}, \ldots, \mathrm{F})$ which are shown in Table 4. Similarly, the 24 possible exchange reactions can be grouped into three sets. Each of these sets corresponds to an NMR differentiable reaction. ${ }^{13}$ These reaction sets are schematically depicted in Fig. 8. Since set I comprises trivial identity reactions, we have formally defined a six-site exchange model with only two exchange rates, denoted $k_{\mathrm{II}}$ and $k_{\mathrm{III}}$. Within this model, only two lines are not affected by exchange, namely those with ${ }^{31} \mathrm{P}$ spin configurations $\alpha \alpha \alpha \alpha$ and $\beta \beta \beta \beta$.

a)

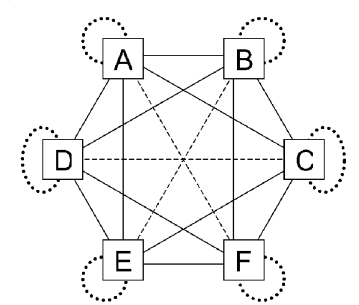

b)

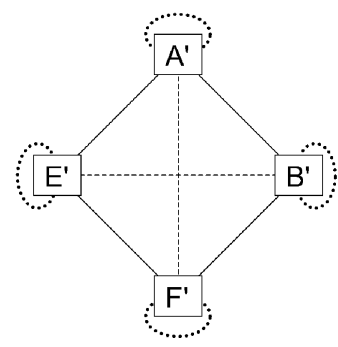

Fig. 8 Graphs showing the topology of the exchange reactions in the six-site (a) and four-site (b) model. Dotted lines correspond to trivial identity reactions in set $\mathrm{I}$; broken lines correspond to double exchange reactions in set II; solid lines correspond to single exchange reactions in set III. See Table 4 for definitions of the permutation classes A, B, . . , $\mathrm{F}$ and $\mathrm{A}^{\prime}, \mathrm{B}^{\prime}, \mathrm{E}^{\prime}, \mathrm{F}^{\prime}$

As can be seen comparing Table 4 with Scheme 1, many nuclear configurations do not agree with the chemical structure of the studied complexes, where each diphosphine is cis ligated to a single platinum atom. If only chemically-sound structures are retained, we are left with eight configurations (bold-face in Table 4), which result in only four equivalence classes $\left(\mathrm{A}^{\prime}, \mathrm{B}^{\prime}\right.$, $\left.\mathrm{E}^{\prime}, \mathrm{F}^{\prime}\right)$ and eight exchange reactions, but again three NMR differentiable reactions. Reaction sets have now a well-defined chemical meaning, as can be appreciated comparing Scheme 1, Table 4, and Fig. 8. Set II consists of the simultaneous exchange of the cis and trans phosphorus nuclei of both diphosphino ligands or, equivalently, of the hydrido and CO ligands. Set III comprises reactions that exchange the cis and trans phosphorus nuclei of a single diphosphine. Therefore, if only chemicallysound structures are allowed, we are left with a four-site 
exchange model with exchange rates $k_{\text {II }}$ and $k_{\text {III }}$. Within this model, the lines not affected by exchange are those with ${ }^{31} \mathrm{P}$ spin configurations $\alpha \alpha \alpha \alpha, \beta \beta \beta \beta, \alpha \beta \alpha \beta$ and $\beta \alpha \beta \alpha$.

The theory of dynamic NMR spectroscopy has been summarized many times. ${ }^{23}$ The transverse components of the magnetization of spin systems that can be treated to first-order and that undergo (possibly pseudo) first-order exchange reactions follow the equation of motion

$$
\frac{\mathrm{d}}{\mathrm{d} t} \vec{M}^{+}=\mathbf{L} \vec{M}^{+}
$$

where the Liouvillian matrix is

$$
\mathbf{L}=\mathrm{i} \Omega-\boldsymbol{\Lambda}+\mathbf{K}
$$

where the elements of the diagonal matrix $\Omega$ correspond to the frequency $\Omega_{p m, p m}$ of the $p$ th transition in the $m$ th site and $\Lambda$ is the transverse relaxation matrix with elements $\Lambda_{p m, q n} . \Lambda$ is usually assumed diagonal with elements

$$
\Lambda_{p m, q n}=\delta_{p q} \delta_{m n} T_{2, p}^{-1}
$$

but off-diagonal elements between degenerate transitions may occur. $\mathbf{K}$ is the kinetic matrix with elements

$$
K_{p m, q n}=\delta_{p q} k_{n m}, m \neq n \text { and } K_{p m, p m}=-\sum_{m \neq n} k_{m n}
$$

where $k_{m n}$ is the rate constant for the reaction from site $m$ to site $n$. At equilibrium, the equation of motion simplifies to

$$
\mathbf{L} \vec{M}^{+} \equiv(\mathrm{i} \mathbf{\Omega}-\mathbf{\Lambda}+\mathbf{K}) \vec{M}^{+}=0
$$

so that the transverse magnetization vector is obtained by diagonalising the complex symmetric matrix $\mathbf{L}$. The complex eigenvalues of $\mathbf{L}$ give the frequency and width of the transitions, while the eigenvectors determine their intensity and phase. ${ }^{24}$ The exchange models detailed above have been formalized within this theoretical framework. Some constraints have been applied: (i) the $J$-couplings have been assumed to be temperature independent; (ii) the homogenous line width $\left(T_{2, p}^{-1}\right)$ has been assumed equal for all transitions in all sites; (iii) when present, all off-diagonal elements of matrix $\boldsymbol{\Lambda}$ have been assumed equal.

The hydrido NMR spectroscopic data amenable to dynamical study are restricted to the sub-spectrum from the isotopomer with no active ${ }^{195} \mathrm{Pt}$ and the higher-field satellite sub-spectrum with a single ${ }^{195} \mathrm{Pt}$ because of extensive overlap in the other spectral regions. Each of these two series of temperature-dependent sub-spectra has been fitted to both the four- and six-site exchange models, and for each model attempts have been made to fit the spectra with reaction set II only, reaction set III only, and with both sets.

Optimization has been carried out by Nelder-Mead Simplex method, a rather slow but very robust algorithm that relies only on the value of the target function (the sum of the squared difference between the experimental and the calculated lineshape) and does not need evaluation of the derivatives of the target function with respect to the fit parameters.

Linear fits of the obtained exchange rate constants to the Arrhenius and Eyring equations have been carried out by the usual least-squares method.

\section{Acknowledgements}

The authors wish to thank the MIUR (A. L. B. and G. B. acknowledge grant PRIN 2002-2004) and the CNR for financial support.

\section{References}

1 See, for example: (a) F. A. Cotton and G. Wilkinson, Advanced Inorganic Chemistry, J. Wiley and Sons, New York, 5th edn., 1988, ch. 27 and 28; (b) G. W. Parshall and S. D. Ittel, Homogeneous Catalysis, J. Wiley and Sons, New York, 2nd edn., 1992.

2 (a) R. D. Adams, B. Captain, W. Fu and P. J. Pellechia, Chem. Commun., 2000, 937, and references therein; (b) Y. Ohki and H. Suzuki, Angew. Chem., Int. Ed., 2002, 41, 2994, and references therein.

3 (a) R. H. Crabtree, The Organometallic Chemistry of the Transition Metals, J. Wiley and Sons, New York, 1988, ch. 10; (b) F. P. Pruchnik, Organometallic Chemistry of the Transition Elements, Plenum Publishing Corporation, New York, 1990; (c) N. Koga and K. Morokuma, in Transition Metal Hydrides, VCH Publishers, New York, 1992, ch. 6

4 See, for example: (a) R. H. Hill and R. J. Puddephatt, J. Am. Chem. Soc., 1983, 105, 5797; (b) D. M. Heinekey, D. A. Fine, T. G. P. Harper and S. T. Michel, Can. J. Chem., 1995, 73, 1116.

5 (a) G. Minghetti, A. L. Bandini, G. Banditelli and F. Bonati, J. Organomet. Chem., 1979, 179, C13; (b) G. Minghetti, A. L. Bandini, G. Banditelli, F. Bonati, R. Szostak, C. E. Strouse, C. B. Knobler and H. D. Kaesz, Inorg. Chem., 1983, 22, 2332; (c) A. L. Bandini, G. Banditelli, M. A. Cinellu, G. Sanna, G. Minghetti, F. Demartin and M. Manassero, Inorg Chem, 1989, 28, 404; (d) A. L. Bandini, G. Banditelli, M. Manassero, A. Albinati, D. Bolognesi and J. Eckert, Eur. J. Inorg. Chem., 2003, 10, 1002.

6 (a) M. Portnoy, F. Frolow and D. Milstein, Organometallics, 1991, 10, 3960; (b) M. Portnoy and D. Milstein, Organometallics, 1994, 13, 600 .

7 I. Tòth and C. J. Elsevier, Organometallics, 1994, 13, 2118.

8 V. N. Zudin, V. D. Chinakov, V. M. Nekipelov, V. A. Likholobov and Y. I. Yermakov, J. Organomet. Chem., 1985, 289, 425.

9 R. J. Abraham, J. Fisher and P. Loftus, in Introduction to NMR Spectroscopy, J. Wiley and Sons, New York, 1988, pp. 72-80.

10 C. B. Knobler, H. D. Kaesz, G. Minghetti, A. L. Bandini, G. Banditelli and F. Bonati, Inorg. Chem., 1983, 22, 2324

11 P. S. Pregosin, Annual Reports on NMR Spectroscopy, ed. G. A. Webb, Academic Press, London, 1986, vol. 17.

12 P. S. Pregosin and R. W. Kunz, in NMR Basic Priciples and Progress, Springer-Verlag, New York, 1979, vol. 16.

13 (a) W. G. Klemperer, J. Am. Chem. Soc., 1973, 95, 380; (b) W. G. Klemperer, in Dynamic Nuclear Magnetic Resonance Spectroscopy, ed. L. M. Jackman and F. A. Cotton, Academic Press, New York, 1975.

14 A. R. Siedle, R. A. Newmark and W. B. Gleason, Inorg. Chem., 1991, 30, 2005.

15 P. E. Garrou, Chem. Rev., 1981, 81, 229.

16 (a) G. Minghetti, A. Albinati, A. L. Bandini and G. Banditelli, Angew. Chem., Int. Ed. Engl., 1985, 24, 120; (b) A. L. Bandini, G. Banditelli and G. Minghetti, J. Organomet. Chem., 2000, 595, 224.

17 T. H. Tulip, T. Yamagata, T. Yoshida, R. D. Wilson, J. A. Ibers and S. Otsuka, Inorg. Chem., 1979, 18, 2332.

18 D. E. Berning, B. C. Noll and D. L. DuBois, J. Am. Chem. Soc., 1999, 121, 11432

19 G. Banditelli and A. L. Bandini, unpublished results.

20 G. Banditelli, A. L. Bandini, G. Minghetti, R. Seraglia and P. Traldi, Rapid Commun. Mass Spectrom., 1996, 10, 1107.

21 B. L. Bennett and D. M. Roddick, Inorg. Chem., 1996, 35, 4703

22 G. Bodenhausen, H. Kogler and R. R. Ernst, J. Magn. Reson., 1984, 58, 370 .

23 (a) G. Binsch, J. Am. Chem. Soc., 1969, 91, 1304; (b) G. Binsch, in Dynamic Nuclear Magnetic Resonance Spectroscopy, ed. L. M. Jackman and F. A. Cotton, Academic Press, New York, 1975; (c) R. R. Ernst, G. Bodenhausen and A. Wokaun, Principles of Nuclear Magnetic Resonance in One and Two Dimensions, Clarendon Press, Oxford, 1991; (d) M. H. Levitt, Spin Dynamics, J. Wiley and Sons, New York, 2001.

24 A. D. Bain and G. J. Duns, Can. J. Chem., 1996, 74, 819. 